\title{
SOME KEY PRINCIPLES IN IMPLEMENTING KNOWLEDGE MANAGEMENT: THE VIEWS OF EMPLOYEES IN A SMALL SOFTWARE COMPANY
}

\author{
CLAIRE WAGNER \\ NAFISA CASSIMJEE \\ Department of Psychology \\ University of Pretoria \\ HANNIE NEL \\ Market researcher
}

\begin{abstract}
As the Knowledge Era replaces the Information Age the challenge is to transform information into knowledge and use this knowledge to create and sustain the competitive advantage of organisations. In this article four key principles for implementing knowledge management are discussed. These principles were derived from a survey and discussions with employees at a small software company. The four principles are: the need for a common definition of and vision for knowledge management, the interdependence between the human and technology track, the way employees punctuate 'knowing' and the structure of a reward system for sharing knowledge.
\end{abstract}

\section{OPSOMMING}

Organisasies word gekonfronteer met unieke uitdagings soos wat die Kennisera die Inligtingsera vervang. Een van die grootste uitdagings is om inligting te verander na betekenisvolle kennis en om die kennis te gebruik om 'n kompeterende voorsprong te skep en te bou. In hierdie artikel word vier kern beginsels vir die implementering van kennisbestuur bespreek. Die beginsels is geskoei op ' $n$ opname van en onderhoude met werknemers in ' $n$ klein sagteware besigheid. Die vier beginsels is: die behoefte aan ' $n$ definisie en visie van kennisbestuur, die interafhanklikheid tussen mense en tegnologie, die wyse waarop werknemers kennis punktueer en die skep van 'n beloningstruktuur vir die deel van kennis.

There is increasing enthusiasm about the wonders delivered by the newest information technologies in an era characterised by knowledge as the critical resource for business activity. The ushering in of the knowledge society is described in literature (see Chattell, 1995; Drucker, 1995; Giddens, 1990) as being a revolutionary transformation in our conceptions of what knowledge is and the way that we regard the role of knowledge in a post-industrial society (Sieloff, 1999).

Before the literature on knowledge management is reviewed, a contrast between the way in which information is viewed in Industrial Age and 21st century organisations may be useful. The environment of the 20th century was stable and predictable, with a domestic market orientation. Organisations could afford to avoid risks and to focus on internal affairs; organisations were characterised by top-down control, rigidity and hierarchy. Size was seen as a sustainable competitive advantage in competing for contemporary markets. Top management closely guarded information using it as an instrument of control where information flowed via the organisational hierarchy (Sveiby, 1997). Organisations operated relatively independently from each other and were pre-occupied with the streamlining of activities, rather than with results (Kiernan, 1996).

In contrast herewith, the environment of the 21st century is characterised by discontinuous change, ambiguity and hyper competition. Speed and responsiveness are of the utmost importance. Organisations have to be flexible, proactive and creative to survive and information needs to be shared between organisation members and even between different organisations. Information is thus a tool for communication - a resource - and flows via 'collegial networks' (Sveiby, 1997).

Thus, the 21st century organisation will look and function very differently from its Industrial Age counterpart in terms of the management of information. Virtual organisations will be established with networks of employees, associates, suppliers,

Requests for copies should be addressed to: C Wagner, Department of Psychology, University of Pretoria, Pretoria, 0002 shareholders and customers communicating more and more through digital technology. Interactive communication will become more important than physical locations. The brainpower of the intelligent business will be the knowledge workers as key creative professionals (Management Trends International, 1998)

The impact of globalisation, technology, diversity and other environmental trends calls for a paradigm shift in management thinking. Organisations that are struggling to cope with the changing pace of their operational and competitive environments could explore concepts such as knowledge management, organisational learning and collaboration (Dove, 1999). In other words, for organisations that want to survive and be successful in the 21st century, there are new rules with different boundaries requiring new and different behaviours inside the boundaries (Luthans, 1995). With the change in behaviour that organisations will experience, new ways of defining, generating and understanding knowledge are implied.

There are however, paradigmatic differences in the understanding of what knowledge is. Traditional definitions of knowledge often equate it to content (Fahey \& Prusak, 1998). In the 21st century organisation, knowledge is equated to process because the demands of new organisations require novel ways of creating and sustaining knowledge. The fusion of information and insights from people and information technology will result in the creation of different boundaries with the consequences of different behaviours in the 21st century organisation. Selective filters were applied to the dissemination of knowledge in the old organisation whereas in the 21 st century organisation technological advances have made it possible for knowledge to be available and accessible at multiple levels.

Research that took place in a traditional organisation was based on collecting information. Information in this context was passive, something 'out there' that had to be gathered and made available to be used when needed (van Ewyk, 1998). Inherent in this description of information is the lack of acknowledgement 
of the interpretive processes of observing systems. In the new organisational context the conditions under which 'knowing' occurs and how knowledge is reconstituted are constantly changing (Scarbrough, 1999). Van Ewyk's (1998, p. 2) understanding of knowledge is that "it is a step beyond information" in that knowledge is produced by metainterpretations of information. The internal dissemination of knowledge in the new organisation should parallel the dynamic conditions underlying knowing.

Young (in Stadler 1999) and Van Ewyk (1998) agree that there are different points of view on what exactly knowledge management entails. Sveiby $(2000$, p. 1) identifies strongly with the human resources perspective and defines knowledge management as "the art of creating value from an organisation's intangible assets". Knowledge management entails "radical and fundamentally new ways to create, share and leverage what each company has, and how to account for it" (Young in Stadler, 1999, p. 19). Young sees the fusion of technology, people and processes as essential in knowledge management. In short, knowledge management combines two fields: information technology and human resources; knowledge management is not either technology or people, but incorporates both and more.

Sveiby (2000) provides a description of the two tracks in knowledge management: the information technology track and the people track. Within the information technology track knowledge management is seen as the management of information. It is about using information technology to leverage knowledge within a company. Thus, the main emphasis is on tools and techniques for capturing, analysing and distributing information such as data-warehousing and data-mining and concepts like the internet, intranet, extranet and collaboration software (e.g. e-mail, online chat groups, shared documents and so on) are dealt with. According to Young (in Stadler 1999, p. 19) "new technologies have emerged that enable teams to better communicate, co-operate, collaborate and co-own projects in ways that have simply not been possible before".

The sharing of knowledge using innovative technology, however, creates a paradox. With greater accessibility to knowledge comes the difficulty with grounding it in a specific context. To overcome this paradox it is necessary to focus not so much on processes of communication, but on changing the context for such processes (Scarbrough, 1999). The sharing of knowledge between members of the organisation creates new networks through which knowledge itself can be redefined in diverse contexts that are themselves continuously changing.

The human resources component deals with organisational change where knowledge management is viewed as the management of people. The people track, although still in its infancy concerning knowledge management applications, is vital to an organisation's ability to innovate and build environments that will enable the creation of new knowledge. Any organisation can purchase knowledge management software, but the ability to create a sustainable creative organisation, according to Sveiby (2000), is difficult. Innovation, therefore, is the only competitive advantage that an organisation has. Spady and Schlebusch $(1999$, p. 18) state that "organisations need and rely on capable, self-starting, innovative and adept employees who can do 'smart work', 'think outside the box', want to learn continuously and improve how they operate, and perform on the cutting edge to help their organisations flourish".

Just as an organisation would invest in information technology, it is also important to invest in people, recruitment, the office environment and so on. Trust between people (management and employees) is paramount. Sveiby (2000) termed this the 'bandwidth of human infrastructure'. While information technology has pioneered the concept of knowledge management, it is essential that the human element should not be ignored. Knowledge management implies an interdependent relationship between people and technology. According to Young (in Stadler, 1999) technology enables knowledge management, while people are the key to the knowledge management process.

Whilst the literature indicates important considerations for implementing a knowledge management strategy there is a paucity of research on employees' perceptions of the implementation process and the underlying principles of its success. The aim of this article is to explore and describe employees' concepts of knowledge management in a small software company and to make recommendations for implementation that takes employees' perceptions into account.

\section{METHOD}

\section{Research design}

A software company requested an internal survey of employees' perceptions of implementing a knowledge management strategy (as part of their general climate study) due to the lack of information on this topic and subsequent guidelines on how to include employees in this process. Due to the fact that the questions on knowledge management were part of the general climate study in the organisation that yielded only quantitative data the researchers decided that follow-up interviews be requested with willing participants to gather more in-depth information about salient points identified quantitatively. The combination of quantitative and qualitative methods allowed for a convergence of information from different sources (Kelly, 1999). This use of triangulation enhanced the validity of the study (Richardson, 1996).

\section{Sample}

The organization has a structure with three levels: Level 1 comprises top management ( 2 people), level 2 senior management ( 2 people) and level 3 web consultants ( 35 people). This company is in the process of implementing a knowledge management strategy. The employees perform various tasks such as selling and developing websites and are therefore computer literate. For this study the respondents were conveniently selected on the basis of their willingness to participate in the study both for the questionnaire and interview phases. Nineteen employees responded to the questionnaire: one from management (level 1 and 2) and eighteen from level 3. Their ages ranged from 18 to 32; eight were female and eleven were male. Eight ( 3 females and 5 males) of the respondents indicated on the questionnaire that they would be available for follow up interviews.

\section{Measurement}

The researchers constructed a questionnaire by formulating questions based on current knowledge management literature and in co-operation with the management of the company. The structured questionnaire consisted of four sections: general dimensions of knowledge management, knowledge management technologies, benefits of knowledge management and the main barriers to knowledge management implementation. In sections one and two respondents were asked to rate items on a 5-point Likert scale where $1=$ strongly disagree and $5=$ strongly agree. Using this format increased the comparability of responses to the different questions (Babbie, 2001) and enabled the researchers, by including a neutral choice in the middle of the scale (Neuman, 2000), to identify respondents with no opinion or those who avoided making a choice. No cases of a respondent constantly choosing the neutral position were found and thus all the data were used for further analysis. Examples of items from sections one and two are: 'Employees are willing to share their knowledge', 'the company has a structure which facilitates the sharing of knowledge' and 'knowledge management is purely a technological solution'. 
In sections three and four respondents were asked to mark the items they considered to be beneficial and main barriers to implementing knowledge management in their company. Examples of these items are: 'faster response time', 'better decision making' and 'product innovation' (benefits); 'lack of time to share knowledge', 'lack of understanding knowledge management' and 'insufficient technology' (barriers). The questionnaire was designed in an HTML format and placed on the company's network. Employees were notified via e-mail of its availability. Javascript language was used to export the data directly to a spreadsheet.

The semi-structured interviews were arranged with the eight follow-up respondents. As an employee of the company the interviewer was familiar with the interviewees which aided rapport. The possible influence of this familiarity on the validity of the results was minimised by the interviewer assuring the interviewees of their anonymity as well as not tape recording the sessions. Notes were therefore compiled during the interview and these were used as the protocols for analysis.

\section{Analysis}

For the purpose of this article items pertaining specifically to knowledge management strategies were selected for analysis, as other items were included in the questionnaire as part of a broader study that pertained to the general operations of the company. Descriptive statistics were used to analyse the quantitative data; frequencies, means and standard deviations were calculated. In sections three and four of the questionnaire the frequency of responses was determined and then rank ordered.

The qualitative protocols were analysed separately by two researchers. Protocols were read to identify meaning units or codes. The codes were then condensed into broad categories and finally condensed further into interrelated themes. The two researchers compared their identified themes and these were collated by means of consensus discussions as to which themes would be included in the final thematic list. This dialogical inter-subjectivity is defined by Kvale (1996, p. 65) as an "agreement through a rational discourse and reciprocal critique among those identifying and interpreting a phenomenon". Engaging in this dialogic process enhanced communicative validity.

\section{RESULTS}

Respondents were asked for their views on knowledge management and the strategies for its implementation. The quantitative data is presented as follows: general views on knowledge management, knowledge management technologies, benefits of implementing knowledge management and the barriers to knowledge management implementation. Following these results the qualitative data is presented to provide a richer description of employees' overall ratings of knowledge management.

\section{Descriptive statistics}

Table 1 outlines the mean scores of employees' ratings of items related to the overall strategies for the implementation of knowledge management.

TABLE 1

MEAN SCORES OF EMPLOYEES' RATINGS OF KNOWLEDGE MANAGEMENT STRATEGIES

\begin{tabular}{llll}
\hline ITEMS & $\underline{\mathbf{N}}$ & $\underline{\mathbf{M}}$ & $\underline{\mathbf{S D}}$ \\
\hline $\begin{array}{l}\text { People and their responses are critical to the success of } \\
\text { knowledge management }\end{array}$ & 19 & 4.47 & 0.61 \\
$\begin{array}{l}\text { The sharing of knowledge should be guided by an } \\
\text { overall knowledge management strategy }\end{array}$ & 19 & 4.26 & 0.56
\end{tabular}

There should be a reward system to encourage the sharing of knowledge

The knowledge management process should be led by a knowledge manager

Cross functional teams is a key success factor in knowledge management

People see IT as part of their normal working practice

Knowledge management is purely a technological solution

From Table 1 it is evident that the respondents are in consensus that people drive the knowledge management process. Technology is not the most important part in the implementation process. In a discussion on new organisations, Chattell (1995) emphasised that the transformation of organisations is not solely driven by implementing technology.

Table 2 contains respondents' ratings of technologies needed to implement knowledge management.

TABLE 2

IMPORTANCE OF KNOWLEDGE MANAGEMENT TECHNOLOGIES

\begin{tabular}{lccc}
\hline ITEMS & $\underline{\mathbf{N}}$ & $\underline{\mathbf{M}}$ & $\underline{\underline{\mathbf{S}}}$ \\
\hline Internet & 18 & 4.50 & 0.99 \\
Document management systems & 19 & 4.11 & 0.99 \\
Data warehousing/mining & 17 & 4.06 & 1.09 \\
Intelligent search agents & 18 & 4.06 & 1.06 \\
Intranet & 19 & 3.89 & 1.24 \\
Decision support systems & 18 & 3.78 & 1.11 \\
Corporate portal & 16 & 3.63 & 0.96 \\
Extranet & 18 & 3.50 & 1.29 \\
\hline
\end{tabular}

The high mean scores for all the items indicate the importance of these enabling structures for achieving successful implementation. Despres and Chauvel (1999) found that intranets and knowledge bases formed an integral part of the information sharing process in organisations.

Improved productivity is regarded as one of the main benefits of knowledge management as outlined in Table 3.

TABLe 3

THE BENEFITS OF KNOWLEDGE MANAGEMENT

\begin{tabular}{lc}
\hline ITEMS & RANK ORDER \\
\hline Improved productivity & 1 \\
Better decision making & 1 \\
Employee development & 2 \\
Faster response time & 3 \\
Better customer-handling & 3 \\
Product innovation & 4 \\
Better morale & 5 \\
\hline
\end{tabular}

The main barriers to knowledge management implementation are presented in Table 4: 
TABLE 4

THE MAIN BARRIERS TO KNOWLEDGE MANAGEMENT

\begin{tabular}{lc}
\hline ITEMS & RANK ORDER \\
\hline Ineffective communication & 1 \\
Lack of funds & 2 \\
Lack of senior management commitment & 2 \\
Lack of time to share knowledge & 3 \\
Lack of understanding knowledge management & 4 \\
Insufficient technology & 5 \\
People are not willing to share knowledge & 6 \\
Little personal benefit for users & 6 \\
\hline
\end{tabular}

It would appear that employees recognize that the main obstacles to the implementation of a knowledge management strategy are not confined to an individual level such as willingness to share knowledge but are more on an organisational level such as ineffective communication.

\section{Interview data}

In response to the question "How do you see knowledge management?" participants' definitions included the following common elements:

- Structured process

- Ordered process

- Flexible system

- Adaptable system

- Distribution system

- Shared system

In the respondents' understanding of knowledge management the terms process and system were used interchangeably. The structured and ordered nature of knowledge management was important to employees because they perceived it as a fundamental element to accessing knowledge within the company in an efficient manner. For the respondents, the idea of efficiency means that information has to be shared regularly and can be applied to diverse contexts "for the right people, the right information, and at the right time". The process encapsulated by respondents indicates a strategic management system of intellectual capital that is derived from the organisation's 'collective knowledge reservoir'. According to Pérez-Bustamante (1999) individuals sharing knowledge and experiences in an organisation create these knowledge reservoirs. The respondents suggested that antecedents to the establishment of a shared system include the existence of a knowledge base within each individual and the willingness of people to impart their knowledge. Although some common elements exist in the definitions of knowledge management, the employees gave different views on what exactly it entails. The implications of these differences for implementing knowledge management will be discussed later.

Collating the data from Table 3 with the themes identified from the qualitative protocols, it appears that productivity is linked to more than just the efficient sharing of information. Effective leadership and communication from management enhance psychological variables such as motivation, attitude and interest. Respondents emphasised that in order to enjoy the advantages of a knowledge management system these organisational dimensions should precede the implementation phase. Respondents also recommended the development of a reward or incentive platform to facilitate the processes necessary for implementation. Discussions with respondents yielded various ideas on the incentive package. These included a reward system that was tangible (financial benefit) and a reward system that was intangible (being acknowledged for having and sharing the knowledge). The dividends of this acknowledgement pertained to issues of power and respect within the company. In essence, respondents propose that a better decision-making system is a direct result of people "learning faster to interpret and use information in a dynamically changing environment".

The following key drivers were identified in the protocols and qualify the meanings attributed to the main barriers to knowledge management implementation presented in Table 4:

- Multilevel communication

- Dynamic leadership

- Commitment

- Cutting edge technology

- Reward platform

Respondents suggested that communication from top management is the driving force to the effective implementation of a knowledge management system. On another level, however, the employees of the organisation are willing to take leadership responsibilities as long as the fundamental implementation strategies are put in place by management. For employees to effectively manage the process on their level, communication must not be on an arbitrary basis, in a piecemeal fashion, done hastily or be asynchronous. Issues concerning trust are stated as barriers to knowledge management implementation and respondents suggest that this arises from poor communication and a lack of effective leadership which creates an environment where "employees receive pieces of the puzzle and then have to piece it together and then get very confused". Although a peoplecentric track is emphasised by respondents, the need for advanced technology in several areas is stipulated as a key driver for knowledge management implementation. Respondents suggested that in addition to the necessary tools there should be a technical knowledge management structure, which could include a server that provides accessibility to a centralised database.

\section{DISCUSSION AND RECOMMENDATIONS}

The researchers would like to emphasise four key principles in the implementation of knowledge management that were identified from the results. The first principle concerns the need for a shared definition of and vision for knowledge management in the company. From the literature discussed in this article and the communication from employees it seems that a single definition of knowledge management is elusive. Due to unique views of what knowledge management is, a difficult situation is created for employees, as they are unsure of how knowledge management should be implemented if there are no specific directives from management. Although a shared definition is elusive, employees concur that a shared context is essential to managing knowledge. Fahey and Prusak (1998) define shared context as employees having a common understanding of the connection between the internal and external environment of the organisation. The prerequisite for aligning the shared context in an organisation is establishing and maintaining open channels of dialogue and critical debate about what knowledge is and how it should be managed. The networking of people in an organisation is vital to the success of effective knowledge exchange (Ruggles, 1998; Wiig, 1998).

The second key principle is contained in the belief that acknowledgement of employees' role in the dialogical process is accompanied by a responsibility for observations, descriptions and explanations. The paradigm shift that organisations need to make to distinguish between information and knowledge compels them to recognise the context of mutually defining relationships that punctuate employees' knowing activities. How the employee punctuates and develops his or her system of knowing and acting is dependent on how the dialogical process impacts on current power structures and emerging experiences of empowerment. Pérez-Bustamante (1999, p. 8) recommends 
that "... the organisation should undertake a proactive approach to achieve the internal dissemination of knowledge, independently of where it was created and how it was deposited" although the autonomy of employees should be encouraged so that they feel free to express their opinions and share their knowledge. In this regard, there should be a search for diversity and complexity in the organisation so that the changes that take place in the work environment can be successfully contained. There may be a catch, however, as according to Pérez-Bustamante (1999, p. 12): "some individuals may perceive that the possession of information grants them a special power and communicating this knowledge could provoke a loss of their competitive advantage", which may lead to feelings of disempowerment. The creation of ways to deal with such issues is a major challenge that must be overcome for the successful implementation of knowledge management. Central to this is the idea of reflexivity, which plays a part in recreating the role of employees and their relationship to management. Scott (1997b) lists reflexivity as one of the five attributes of the emerging knowledge society. Reflexivity in this context alludes to the interaction between what an employee may describe of specific events and how that description is also part of the event. By engaging in the 'reflexive turn' organisations can promote the equal validity of the employees' voices as well as emphasising and analysing the employees' role in constructing the knowledge process and the results thereof (Burr, 1995).

A third key principle is concerned with employees' recognition of the importance of developing an appropriate reward system that can be coupled to sharing knowledge. A KPMG report (1998) found that employees want to be rewarded for taking initiatives to implement knowledge management as well as participate in determining the structure of incentive packages. One suggestion is that employees be allowed to participate in self-enhancement activities in return for sharing their knowledge. When employees participate in knowledge sharing the conventional reward structures that are designed to deal with immediate monetary reward do not always apply. This is because the benefits of knowledge management are contained in long term processes. The incentive packages have to be designed to include 'factored non-monetary' rewards that can be given to employees based on the mutual definition of roles in the knowledge process. Fahey and Prusak (1998) and Teece (1998) have suggested ways of quantifying the value of the intangible assets created by implementing a knowledge management strategy. One example of this is attaching value to the intellectual property when a company sells a patent.

The fourth key principle is the interdependence between the human and technology tracks. Although technology can be used to capture, develop and distribute knowledge this knowledge cannot originate or fully exist independent of a person. Investing solely in technology is a one-dimensional approach to change and transformation that discounts the existence of two distinct forms of knowledge. The first form is explicit knowledge, which is something that can be categorised, stored, published and distributed. It includes databases about employees' skills, the buying behaviour of customers, and so on. This type of information is usually available within a company and knowledge management programmes are established to deal with this type of knowledge. The second form, tacit knowledge, is more difficult to define. It is "developed through experience, thinking, observation and intuition" (Backweb Technologies, 2001, p. 2), it is "in the minds of people" (Miller, 1999, p. 2). Focusing solely on the technology track fulfils the criteria for explicit knowledge generation. Tacit knowledge can only be created within a knowledge management strategy when the organisation realises that the people factor is vital; "if technology solves your problem, yours was not a knowledge problem" (Ruggles, 1998, p. 88). Organisations that embrace new technologies should not do so to replace the contributions of employees but rather to amplify their potential (Chattell, 1995).
Establishing a successful knowledge management strategy is dependent on a knowledge-based culture and a proactive approach to communication (Pérez-Bustamante, 1999). In other words the common definitions of knowledge management should be constructed within the organisational environment. Central to this is the stochastic process known as learning. Learning is stochastic in the sense that it combines random and selective processes in such a way that only certain outcomes of the random are allowed to endure. Random processes in this sense refer to the innovative knowledge behavioural repertoires performed by individuals in the organisation. The successful outcomes of these random behaviours that endure are related to an order of learning that Bateson (1972) called deutero-learning. Learning of this kind may be described as learning how to learn. This means that employees would look for strategies for trying out new behaviours, and those strategies that yield success survive, become part of the collective knowledge reservoir and are incorporated in the structural capital of the organisation. In order for deutero-learning to be established and maximized the knowledge management environment should incorporate the hierarchical structure of the knowledge process.

It is therefore recommended that the primary task for any organisation wanting to implement a knowledge management strategy begins with creating working common definitions of knowledge pertinent to that organisation. The definition of knowledge as a process inseparable from those who create it allows employees to use technology as an enabler rather than as a replacement thus balancing the human-technology interface. The negotiated balance between people and computers is encapsulated in the employees' punctuation of their knowing activities and the boundaries of such activities. These functions have tangible and intangible outcomes and therefore the reward system must incorporate these elements in order to maintain the principles of a knowledge management strategy.

The key principles outlined by the respondents suggest that knowledge management embodies organisational processes that seek a synergistic combination of data and the information processing capacity of information technologies, and the creative and innovative capacity of human relations. The creation of knowledge occurs on many levels and is influenced by the organisational context, technological media and the human-technology interface.

\section{REFERENCES}

Babbie, E. (2001). The practice of social research (9th ed.). Belmont: Wadsworth/Thomson Learning.

Backweb Technologies. (2001). Knowledge management: an industry perspective sponsored by Backweb Technologies. [Online]. Available: http://www.backweb.com [2001, February 28].

Bateson, G. (1972). Steps to an ecology of mind. New York: Ballantine.

Burr, V. (1995). An introduction to social constructionism. London: Routledge.

Chattell, A. (1995). Managing for the future. London: Macmillan Press.

Depres, C. \& Chauvel, D. (1999). Knowledge management(s). Journal of knowledge management, 3(2), 110-120.

Dove, R. (1999). Knowledge management, response ability, and the agile enterprise. Journal of knowledge management, 3(1), 18-35.

Drucker, P.F. (1995). Managing in a time of great change. New York: Truman Talley Books.

Fahey, L. \& Prusak, L. (1998). The eleven deadliest sins of knowledge management. California management review, 40(3), $265-276$

Giddens, A. (1990). The consequences of modernity. Stanford: Stanford University Press. 
Kelly, K. (1999). Calling it a day: reaching conclusions in interpretive research. In M. Terre Blanche and K. Durrheim (eds), Research in practice: Applied methods for the social sciences (pp. 421-437). Cape Town: University of Cape Town Press.

Kiernan, M.J. (1996). The eleven commandments of 21st century management. Englewood Cliffs, New Jersey: Prentice Hall.

KPMG. (1998). Knowledge Management. (Report by KPMG management consulting). London: KPMG.

Kvale, S. (1996). Interviews. An introduction to qualitative research interviewing. Thousand Oaks: Sage.

Luthans, F. (1995). Organizational behavior. New York: McGraw-Hill.

Management Trends International. (1998). The International Knowledge Management Newsletter [Online]. Available: http://www.mjm.co.uk/knowledge/repch1.html [2000, August 14].

Miller, J. (1999, June). Knowledge management in South Africa. Paper presented at the Knowledge Management Beyond 2000 Seminar, Midrand.

Neuman, W.L. (2000). Social research methods. Qualitative and quantitative approaches (4th ed.). Boston: Allyn and Bacon.

Pérez-Bustamante, G. (1999). Knowledge management in agile innovative organisations. Journal of knowledge management, 3(1), 6-17.

Richardson, J.T.E. (Ed.) (1996). Handbook of qualitative research methods for psychology and the social sciences. Leicester: British Psychological Society.

Ruggles, R. (1998). The state of the notion: knowledge management in practice. California management review, 40(3), 80-89.
Scarbrough, H. (1999). Network nirvana: The management of knowledge in the postmodern organisation [Online]. Available: http://bprc.warwick.ac.uk/wp1.htm [2000, August 14].

Scott, P. (1997b). The crisis of knowledge and the massification of higher education. In R. Barnett and A. Griffin (eds), The end of knowledge in higher education (pp. 14-26). London: London Institute of Education.

Sieloff, C.G. (1999). "If only HP knew what HP knows": the roots of knowledge management at Hewlett-Packard. Journal of Knowledge Management, 3(1), 47-53.

Spady, W.G. \& Schlebusch, A. (1999). CURRICULUM 2005. A guide for parents. Cape Town: Renaissance.

Sveiby, K.L. (1997). The new organisational wealth. Managing and measuring knowledge-based assets. San Francisco: BerrettKoehler.

Sveiby, K.L (2000). What is knowledge management? [Online]. Available: http://www.sveiby.com.au/Knowledge Management.html [2000, August 14].

Stadler, C (1999). Creating a fusion. An interview with Ron Young. Knowledge management, 1(2), 18-24.

Teece, D.J. (1998). Research directions for knowledge management. California management review, 40(3), 289-292.

Van Ewyk, O. (1998). Preparing for the knowledge era. Keynote address to the MIS98 MindShare Conference, Wirrina Cove Resort, Australia [Online]. Available: http://www.hci.com.au/hcisite/articles/prepare.htm [2000, August 14].

Wiig, K.M. (1999). What future knowledge management users may expect. Journal of knowledge management, 3(2), $155-165$ 